\title{
Knowledge and Attitude Regarding Condom Among College Students in Bangladesh
}

\author{
Mosammat Beauty Begum ${ }^{1, *}$, Muhammed Tajul Islam², Abu Sayeed Mohammad Anwarul Kabir ${ }^{3}$ \\ ${ }^{1}$ National Institute of Diseases of the Chest and Hospital (NIDCH), Mohakhali, Dhaka, Bangladesh \\ ${ }^{2}$ Coxsbazar Medical College Hospital, Coxsbazar, Bangladesh \\ ${ }^{3}$ Sylhet MAG Osmani Medical College, Sylhet, Bangladesh
}

Email address:

beautymsn2017@gmail.com (M. B. Beauty)

*Corresponding author

\section{To cite this article:}

Mosammat Beauty Begum, Muhammed Tajul Islam, Abu Sayeed Mohammad Anwarul Kabir. Knowledge and Attitude Regarding Condom Among College Students in Bangladesh. International Journal of HIV/AIDS Prevention, Education and Behavioural Science.

Vol. 6, No. 1, 2020, pp. 1-9. doi: 10.11648/j.ijhpebs.20200601.11

Received: January 28, 2020; Accepted: February 13, 2020; Published: February 19, 2020

\begin{abstract}
Background: Condom is the most popular barrier methods of family planning. Using condom is the only contraceptive method that can protect against both unwanted pregnancy and sexually transmitted diseases including HIV / AIDS and prevent up to $80-95 \%$ of HIV/AIDS transmission. Objective: To assess the knowledge and attitude regarding condom among college students in Bangladesh. Methods: A descriptive correlational study was conducted with a sample of 172 those were randomly selected from selected college of Dhaka city, Bangladesh. Data were collected by the researcher using face-to-face interview with developed questionnaire of 54 items in 2 dimensions Knowledge and Attitude regarding condom. Data were analyzed using descriptive statistics and inferential statistics two sample t-test, ANOVA and Pearson correlation. Results: The mean age of the students was 18.01 years, $80.2 \%$ of them were Muslim. Only $22.7 \%$ of the female students were married. All of them were satisfactory knowledge but 52.9\% had negative attitude regarding condom. Findings showed that higher knowledge regarding condom was significantly related with student's higher age $(\mathrm{F}=27.14 ; p=.000)$, education ( $\mathrm{t}=6.276 ; p=.000)$, father's $(\mathrm{F}=30.851 ; p=.000)$, and mother's $(\mathrm{F}=3.222 p=.042)$ occupation of job and business, more than 4 family members $(\mathrm{F}=11.086 ; p=.000)$, higher monthly family income $(\mathrm{F}=22.703 ; p=.000)$, known someone with STDs $(\mathrm{t}=-6.702 ; p=.000)$, joined to any seminar $(\mathrm{t}=-15.322 ; p=.000)$, and had source of information about condom $(\mathrm{r}=.712$; $p=.000)$ than others. Female students showed significantly $(\mathrm{t}=-3.719 ; p=.000)$ positive attitude than male. Student's those father's occupation were job and business $(\mathrm{F}=7.078 ; p=.001)$, more than 4 family members $(\mathrm{F}=5.652 ; p=.004)$, known someone with STDs $(\mathrm{t}=-2.606 ; p=.010)$ and joined to any seminar $(\mathrm{t}=2.584 ; p=.001)$ about STDs showed significantly positive attitude regarding condom than other. Muslim had significantly $(\mathrm{t}=-2.871 p=.005)$ negative attitude towards condom than other. The relationship of knowledge and attitude regarding condom were revealed positive correlation $(\mathrm{r}=.955 ; p=.004)$. Conclusion: Result suggested that age, sex, religion, education, source of information, knowledge of condom was influenced to attitude regarding condom. Therefore, nursing educational program on condom is recommended.
\end{abstract}

Keywords: Condom, Knowledge, Attitude, College, Student, Bangladesh

\section{Introduction}

Condom is the most popular barrier methods of family planning. Unprotected sex causes many unintended pregnancies and sexually transmitted diseases (STDs). Using condom is the only contraceptive method that can protect against both pregnancy and sexually transmitted diseases including HIV (Human Immune Virus) / AIDS (Acquired Immuno-Deficiency Syndrome) [10, 24]. In most of the world, family planning programs have had great success in slowing population growth and improving women's reproductive health status by providing services to married 
couples. Family planning saves lives of women and children and improves quality of life [2, 24].

Globally, contraceptives prevalence rate increased [22], about 44 million couples use condom during intercourse for family planning while $60 \%$ of all condom are used outside married [7]. In Europe, the role of male condom for both contraception and prevention of STI were established during this century [13]. A study on knowledge and attitude towards condom conducted in Egypt revealed that about $60 \% \mathrm{~S}$ of the participants was considered condom as an effective contraceptive and prevention method of STIs [12]. On the other hand, a study which was conducted in Pakistan, showed low knowledge level regarding appropriate use of condom among contraceptives users [6]. Another study showed a significant relationship between general attitude and use of condom among undergraduate students of a public university in Kenya [16].

Bangladesh has passed a remarkable demographic transition period. The total fertility rate (TFR) per women of reproductive age to 2.3 in 2011 . The declined associated with a reduced total fertility rate from five children in 2005 to two children in 2011. Bangladesh is a country where the adolescent fertility rate is relatively high. Most of these teenage pregnancies occur within the confines of marriage due to the cultural practice of early marriage. It is about 73 per 1000 girls aged 15-19 years [23]. According to the DHS 2007, while About 56\% of married women aged 25-34 years were using modern method of contraception, only two-third of percentage i.e. about $38 \%$ married teenage girls were using a family planning method.

If pregnancy occurs before adolescents are fully developed, they can be exposed to particularly acute health risks including damage to the reproductive health tract, delayed or obstructed labor, ruptures in the birth canals and elevated risks of the maternal mortality [3]. Condom is shown to reduce unwanted pregnancies, most infectious diseases (STIs) and gynecological diseases also $[19,21]$. Babies born to adolescent may experience more birth injuries, and infant mortality which is highest in those countries with in the largest proportion of adolescent births [15]. A study in Kenya among secondary college students revealed that, majority of the participants agreed that condom could not be used more than once and condom use may not be an effective tool in protecting them against HIV/AIDS. Misconception about condom also existed [17].

In Bangladesh, first HIV/AIDS case was report in 1989, by December 2008 , the total number of reported cases was 1,495 [22]. The National AIDS /STDs program (NASP) has an estimate of 7,500 cases, where as an UNAIDS reports has to be as high as $12,000[19,21]$. Adolescents are the highest risk group to be infected by HIV/ AIDS in worldwide [8]. In developing countries, adolescents have less opportunity to receive education on sex and reproductive health. With limited exposure and knowledge, they are more vulnerable to HIV/AIDS [1]. In Bangladesh pills and injectable are most preferred contraceptives method. Use of condom is very low $(5 \%)[19,22,23]$. Whenever it used every time correctly in the approved manner condom could prevent up to $80-95 \%$ of HIV/AIDS transmission [19, 23].

Different studies suggested that knowledge and information about condom as well as positive attitude towards condom use through awareness and educational program on safe sex practice by using condom can be preventing STIs including HIV/AIDS transmission as well as unwanted pregnancies [6, 12, 14, 16, 17]. In Bangladesh, a few study was conducted on knowledge and attitude regarding condom among college students. Therefore, health professionals for example nurses should encourage students to gain knowledge about condom and safe sex. Existing studies found that significance relationship between knowledge and attitude regarding condom [14, 16]. Findings of this study would contribute in developing strategy to improve knowledge about condom to increase social awareness.

Objectives

General objective

The aim of this study was to assess the knowledge and attitude regarding condom among college students in Bangladesh.

\section{Specific objectives}

1. To describe the socio-demographic and condom related characteristics among college students in Bangladesh.

2. To assess the knowledge and attitude regarding condom among college students in Bangladesh.

3. To examine the relationship between socio-demographic characteristics and knowledge and attitude regarding condom among college students in Bangladesh.

\section{Materials and Methods}

This descriptive correlational study was carried out on all Bangladeshi students who were attending at selected college, Dhaka, Bangladesh from January 2012 to December 2012. A total 172 adult subjects (male and female) with the range of 16-19 years of age were for in this study.

Study Design: A descriptive correlational study was conducted.

Study Location:

This is a famous college in Dhaka city which offers both female and male students for all category people come from all over the country. Thus this school and college is a representative setting for getting eligible samples of the target population for this study.

Study Duration: April 2012 to April 2017

Sample Size: 172 students both male and female students.

Sample size calculation:

The sample size was determined by using $G$ power analysis. The estimated sample size has calculated for an accepted minimum level of significant alpha $(\alpha)$ of 0.05 , an expected power of $0.80(1-\beta)$ and accepted medium effect size of $0.30(\gamma)$ calculated sample size is 143 . Due to potential dropout, $20 \%$ attrition rate added and the total 
sample size was 172 .

Subject \& selection method:

Random sampling technique was used to recruit the sample from students registered who were attending at selected college, Dhaka, Bangladesh from January 2016 to December 2016 who met the inclusion criteria.

Inclusion criteria:

1. All students who were eligible and willingly agree to participate in the study.

2. Age between 16-19 years during study periods were included in this study.

Exclusion criteria:

1. Students who were mentally retarded.

2. Age over 19 years during study period.

3. Unregistered students at selected college.

Procedure methodology:

Written Approval was obtained from Department of Public Health Dissertation Defense Committee of State University of Bangladesh (SUB) at Dhaka in Bangladesh. Informed consent was obtained prior to the interview from study participants. Privacy and confidentiality of the participants were maintained. The participation of the student was voluntary and participants could refuse and withdraw from the study at any time without any penalty.

Data collection procedure was divided into two parts:

Preparation phase: The researcher informed and collected verbal permission from Principal of the selected colleges as well as written permission from participants.

Data collection phase: The researcher met with the participants; informed them about the study and human rights and protection, after obtaining consent from, participants who were willingly to participate in the study. The researcher explained about questionnaire and offered to give answer to complete the questionnaire. The researcher collected answer by direct face-to-face interview of the participants to ensure completeness and correctness, it was taken 15-20 minutes.

After completing the questionnaire, the researcher thanked the participants for spending time to participate in this study. This process was continued until desired sample found. Data were collected from students who were attending at selected colleges, Dhaka, Bangladesh from January 2016 to December 2016 with following instrument:

It was measured by 3 parts questionnaires. (1) Sociodemographic Characteristics Questionnaire, (2) Knowledge scale regarding condom, (3) Attitude Scale regarding condom. Questionnaire (SCQ) were developed by researcher based on literature review.

Three experts on public health was validated this questionnaire. Pilot test was done on 30 students. The reliability of the questionnaire (BSEQ) was 0.7 . The results did not include in this study.

(1) The Socio-demographic consisted of 14 items - age, sex, religion, marital status, level of education, occupation of father, occupation of mother, monthly income of family, Total number of family member, have heard about condom, source of information. history of any sexually transmitted diseases (STDs), and known person of any sexually transmitted diseases, history of any attained STDs related seminar.

(2) This study used 2 parts of questionnaires (scale).

(a) Knowledge Scale regarding condom: There are total 15 items of question to assess the knowledge of participants about condom. For positive Knowledge, items score '2' was used for correct answer (true response), '1' for don't know and ' 0 ' for incorrect that means (false responses) was applied. Assessment of level of knowledge was out of $100 \%$ and by using blooms classification, a score of less than $60 \%$ indicated poor knowledge while as a score of $60 \%-100 \%$ indicates positive knowledge which was further classified as follows; $60 \%-85 \%$ indicates satisfactory knowledge and score of $86 \%-100 \%$ indicates good knowledge.

(b) Attitude Scale towards condom: There are total 25 items of question with 5point rating scale to measure the attitude of participant towards condom. For attitude items, 5point 'Likert scale (strongly agree/agree/neutral/strongly disagree/disagree) will be used. For a positive attitude items, a score of 4, 3, 2, 1 and 0 was used for strongly agree, agree, neutral, disagree, strongly disagree respectively was used. Level of attitude was score out of 100 A score of 51-100 indicates positive attitude while as a score of 0-50 indicates negative attitudes. These measures have translated in Bengali version based on back translation process.

\section{Statistical analysis:}

Data was analyzed using SPSS software (version 23). Both descriptive and inferential statistics were used for the analysis of data. The descriptive statistics was used for the analysis of the participant's characteristics, distribution of knowledge, and attitudes of the participants regarding condom in terms of frequency, percentages, mean, and standard deviation and inferential statistics such as chi square, two sample t-test, ANOVA, and Pearson correlation were used to examine the relationship between study variables, $p$ value of $<0.05$ was considered as statistically significant.

\section{Results}

\subsection{Socio-Demographic Characteristics of the Participants}

Total 172 participants were recruited for this study. The mean age of the participants was 18.01 years $(\mathrm{SD}=.90)$ with the range of 16-19 years of age. Most of them were Muslim $(80.2 \%)$ by their religion. Among all $50 \%$ participants had HSC $1^{\text {st }}$ year and rest of them had HSC $2^{\text {nd. }}$ Only $22.7 \%$ of the female participants were married. All of the participants were student and their mean monthly family income was 27476.74 with the range of 15000-50000 BDT. More than half (57.0\%) of the participant's father's occupation were job and two third (75.0\%) of the participant's mother's occupation were homemaker. Only $15.1 \%$ participant's family member were 7-8 persons and more than half $(55.8 \%)$ of the participant's family members were 5-6 persons (Table 1). 
Table 1. The Distribution of Socio-Demographic Characteristics of the Participants.

\begin{tabular}{llll}
\hline Variables & Categories & n & (N=172) \% \\
\hline Age & 16yrs & 7 & 4.1 \\
& $17 \mathrm{yrs}$ & 48 & 27.9 \\
& 18 & 54 & 31.4 \\
& 19 & 63 & 36.6 \\
Sex & Male & 86 & 50 \\
& Female & 86 & 50 \\
Religion & & & \\
& Muslim & 138 & 80.2 \\
Marital Status & Others & 34 & 19.8 \\
& & & \\
\multirow{2}{*}{ Educational Level } & Married & 39 & 22.7 \\
& Unmarried & 133 & 77.3 \\
& & & \\
Occupation of father & HSC 1 $1^{\text {st }}$ year & 86 & 50 \\
& HSC 2nd year & 86 & 50 \\
& & & \\
& Farmer & 23 & 13.4 \\
& Job & 98 & 57.0 \\
& Business & 51 & 29.7 \\
\hline
\end{tabular}

Table 1. continued.

\begin{tabular}{llll}
\hline Variables & Categories & n & \% \\
\hline Occupation of mother & Homemaker & 129 & 75.0 \\
& Job & 29 & 16.9 \\
& Garments worker & 14 & 8.1 \\
Monthly Income in BDT & & & \\
& $15000-25000$ & 87 & 50.6 \\
& $26000-35000$ & 67 & 39.0 \\
Total number of family members & $36000-50000$ & 18 & 10.5 \\
& $3-4$ & 50 & 29.1 \\
& $5-6$ & 96 & 55.8 \\
& $7-8$ & 26 & 15.1 \\
\hline
\end{tabular}

\subsection{Condom Related Characteristics of the Participants}

All of the participants had heard about condom. Majority of the participants $(87.2 \%)$ source of information about condom were radio, T. V and Newspaper and only $12.2 \%$ participants source of information was Internet. None of the participants had history of STDs in their family but more than half $(57.0 \%)$ of the participants were known someone who were suffering from STDs. Among all them only $22.7 \%$ of the participants had joined to a seminar of STDs (Table 2)

Table 2. The Distribution of Condom Related Characteristics of the Participants.

\begin{tabular}{llll}
\hline Variables & Categories & $\mathbf{n}$ & $\begin{array}{l}(\mathbf{N}=172) \\
\mathbf{\%}\end{array}$ \\
\hline Have you ever heard about condom & Yes & 172 & 100 \\
& No & .00 & .00 \\
Source of information about condom & & & \\
Radio, TV, News paper & Yes & 150 & 87.2 \\
& No & 22 & 12.8 \\
Book \& magazine & Yes & 92 & 53.5 \\
& No & 80 & 46.5 \\
\hline
\end{tabular}

\begin{tabular}{llll}
\hline Variables & Categories & n & $\begin{array}{l}\text { (N=172) } \\
\mathbf{\%}\end{array}$ \\
\hline Poster\& billboard & Yes & 110 & 64.0 \\
& No & 62 & 36.0 \\
Peers/ friends & Yes & 116 & 67.4 \\
& No & 56 & 32.6 \\
Internet & Yes & 21 & 12.2 \\
& No & 151 & 87.8 \\
Family members & & & \\
& Yes & 28 & 16.3 \\
Family History of STDs & No & 144 & 83.7 \\
& & & \\
Known someone with STDs & Yes & .00 & \\
& No & 172 & 100 \\
Have joined any seminar about STDs & Yes & 98 & 57.0 \\
& Yes & 74 & 43.0 \\
*Multiple Responses & No & 133 & 22.7 \\
\hline
\end{tabular}

\subsection{Knowledge of Participants Regarding Condom}

Table 3 showed that all the participants knew that condom is a contraceptive method of family planning and about 79.1\% participants were aware that condom allows planned family. But less than $10 \%$ participants knew family planning program provides medical services $(7.6 \%)$ and nutritional counselling $(7.0 \%)$ also respectively. Among all participants less than $50 \%(45.3 \%)$ were aware that family planning program provides sexual counselling and also condom is available. On the other hand, only $23.8 \%-26.7 \%$ participants knew that condom reduces unsafe abortions and keeps mother and child healthy respectively. Near about two third (72.7\%) were aware about condom prevents and control of STDs and HIV. Among all of them more than $60 \%$ (62.8\%$69.2 \%$ ) of the participants knew that family planning program provides pre-marital counselling, condom control of family size, maintains child spacing and also prevents unplanned pregnancy.

Table 3. The Distribution of Knowledge of Participants Regarding Condom.

\begin{tabular}{lll}
\hline & \multicolumn{2}{l}{$(\mathbf{N}=\mathbf{1 7 2})$} \\
\cline { 2 - 3 } Items & $\mathbf{n}$ & $\mathbf{\%}$ \\
\cline { 2 - 3 } & 172 & 100 \\
\hline $\begin{array}{l}\text { Condom is a contraceptive method of family } \\
\text { planning }\end{array}$ & 13 & 7.6 \\
$\begin{array}{l}\text { Family planning program provides Medical services } \\
\text { Family planning program provides pre-marital } \\
\text { counselling }\end{array}$ & 108 & 62.8 \\
$\begin{array}{l}\text { Family planning program provides parenthood } \\
\text { counselling }\end{array}$ & 28 & 16.3 \\
$\begin{array}{l}\text { Family planning program provides sexual } \\
\text { counselling }\end{array}$ & 78 & 45.3 \\
$\begin{array}{l}\text { Family planning program provides nutritional } \\
\text { counselling }\end{array}$ & 12 & 7.0 \\
$\begin{array}{l}\text { Condom control of family size } \\
\text { Condom maintains child spacing }\end{array}$ & 108 & 62.8 \\
$\begin{array}{l}\text { Condom prevents unplanned pregnancy } \\
\text { Condom prevents and control of STDs and HIV }\end{array}$ & 119 & 69.2 \\
\hline
\end{tabular}




\begin{tabular}{lll}
\hline \multirow{2}{*}{ Items } & \multicolumn{2}{l}{$\mathbf{( N = 1 7 2 )}$} \\
\cline { 2 - 3 } & \multicolumn{2}{l}{ Correct response } \\
\cline { 2 - 3 } & $\mathbf{n}$ & $\mathbf{\%}$ \\
\hline Condom keeps mother and child healthy & 46 & 26.7 \\
Condom reduces unsafe abortions & 41 & 23.8 \\
Condom is available & 78 & 45.3 \\
Condom is easy and cheap & 95 & 55.2 \\
Condom allows planned family & 136 & 79.1 \\
\hline
\end{tabular}

\subsection{Attitude of Participants Towards Condom}

Table 4 findings showed that among all of the participants only $14.5 \%$ of the participants were "agree "to the statement of condom is an effective method of birth control and $25.6 \%$ of them were 'agree' and 'strongly agree' with the statement of Condom is a highly satisfactory form of contraception. Most of the $(73.8 \%)$ of the participants accepted (agree' and 'strongly agree') that men who suggest using condom really boring and also $73.3 \%$ of the participants accepted (agree' and 'strongly agree') that women think men who use condoms are jerks. Although all of the participants were agree and strongly agree with the statement of "condom will help me to prevent from STDs and HIV" but only $13.9 \%$ of them accepted (agree' and 'strongly agree') with the statement of "Generally, I am in favor of condom" and 70.4\% of them were accepted with the statement of "The idea of using condom does not appeal me". Though majority $(80.0 \%)$ of the participants were denied (disagree and strongly disagree) about the statement of "I do not think that buying condom is awkward" but $82 \%$ of them were accepted with the statements of "When I need condoms I often dread having to get them" and also $100 \%$ of them were agree' and 'strongly agree to statements of the "When I discuss about condom use, almost feel embarrassed" and "It is very embarrassing to buy condoms" and also "It would be very embarrassing to be seen buying condoms from a store" respectively. Among all of the participants two-third (75.6\%) of them were neutral with the statement of "Use of condom interfere with romance" and $69.2 \%$ of them accepted that "Using condom makes me feel very funny" and also more than half $(55.3 \%)$ of the participants agree and strongly agree to "It is really boring to suggest for using condom to my friends".

Table 4. The Distribution of Attitude of Participants Regarding Condom.

\begin{tabular}{|c|c|c|c|c|c|c|}
\hline & & & & & & $(\mathrm{N}=172)$ \\
\hline Items & $\begin{array}{l}\text { Strongly } \\
\text { agree } \\
\text { n (\%) }\end{array}$ & $\begin{array}{l}\text { Agree } \\
\text { n (\%) } \\
\text { n (\%) }\end{array}$ & $\begin{array}{l}\text { Neutral } \\
\text { n (\%) }\end{array}$ & $\begin{array}{l}\text { Disagree } \\
\text { n (\%) }\end{array}$ & $\begin{array}{l}\text { Strongly } \\
\text { Disagree } \\
\text { n (\%) }\end{array}$ & $\mathbf{M} \pm \mathbf{S D}$ \\
\hline Condom is an effective method of birth control & .00 & $25(14.5)$ & $97(56.4)$ & $39(22.7)$ & $11(6.4)$ & $1.79 \pm .77$ \\
\hline Condom is a highly satisfactory form of contraception. & $10(5.8)$ & $34(19.8)$ & $81(47.1)$ & $36(20.9)$ & $11(6.4)$ & $1.98 \pm .95$ \\
\hline I think condom is an excellent means of contraception. & .00 & .00 & $133(77.3)$ & $28(16.3)$ & $11(6.4)$ & $1.71 \pm .58$ \\
\hline Condoms do not offer reliable protection. & .00 & $60(34.9)$ & $76(44.2)$ & $25(14.5)$ & $11(6.4)$ & $2.08 \pm . .86$ \\
\hline Men who suggest using condom really boring & $78(45.3)$ & $49(28.5)$ & .00 & $34(19.8)$ & $11(6.4)$ & $2.87 \pm .1 .35$ \\
\hline $\begin{array}{l}\text { If a couple is about to have sex and man suggests using a condom, it } \\
\text { is less likely that they will have sex. }\end{array}$ & .00 & .00 & $124(72.1)$ & $20(11.6)$ & $28(16.3)$ & $1.56 \pm . .76$ \\
\hline Women think men who use condoms are jerks. & $45(26.2)$ & $81(47.1)$ & .00 & $11(6.4)$ & $35(20.3)$ & $2.52 \pm 1.461$ \\
\hline $\begin{array}{l}\text { Women/ men who suggests using a condom does not trust he/his } \\
\text { partner. }\end{array}$ & $37(21.5)$ & $41(23.8)$ & $16(9.3)$ & $30(17.4)$ & $48(27.9)$ & $1.94 \pm 1.55$ \\
\hline People who suggest condom use are a little bit geeky. & $83(48.3)$ & $75(43.6)$ & .00 & $14(8.1)$ & .00 & $3.32 \pm .84$ \\
\hline When I discuss about condom use, almost feel embarrassed & $116(67.4)$ & $56(32.6)$ & .00 & .00 & .00 & $3.67 \pm .47$ \\
\hline It is really boring to suggest for using condom to my friends & $71(41.3)$ & $24(14.0)$ & $47(27.3)$ & $30(17.4)$ & .00 & $2.79 \pm 1.16$ \\
\hline $\begin{array}{l}\text { I never know what to say when my partner and I need to talk about } \\
\text { condoms or other protection. }\end{array}$ & $65(37.8)$ & $33(19.2)$ & $74(43.0)$ & .00 & .00 & $2.95 \pm .90$ \\
\hline When I need condoms I often dread having to get them & $64(37.2)$ & $77(44.8)$ & $31(18.0)$ & .00 & .00 & $3.19 \pm .72$ \\
\hline It is very embarrassing to buy condoms & $101(58.7)$ & $71(41.3)$ & .00 & .00 & .00 & $3.59 \pm .49$ \\
\hline $\begin{array}{l}\text { It would be very embarrassing to be seen buying condoms from a } \\
\text { store }\end{array}$ & $101(58.7)$ & $71(41.3)$ & .00 & .00 & .00 & $3.59 \pm .49$ \\
\hline I always feel uncomfortable when I buy condoms & $77(44.8)$ & $55(32.0)$ & $13(7.6)$ & .00 & $27(15.7)$ & $2.90 \pm 1.39$ \\
\hline I do not think that buying condom is awkward & $10(5.8)$ & $11(6.4)$ & $13(7.6)$ & $46(26.7)$ & $92(53.5)$ & $2.90 \pm 1.39$ \\
\hline The idea of using condom does not appeal me & $34(19.8)$ & $87(50.6)$ & $51(29.7)$ & .00 & .00 & $2.90 \pm .70$ \\
\hline Generally, I am in favor of condom & $10(5.8)$ & $14(8.1)$ & $103(59.9)$ & $16(9.3)$ & $29(16.9)$ & $1.77 \pm 1.02$ \\
\hline Condom will help me to prevent from STDs and HIV & $53(30.8)$ & $73(42.4)$ & $46(26.7)$ & .00 & .00 & $3.04 \pm .76$ \\
\hline Use of condom interfere with romance & $28(16.3)$ & .00 & $130(75.6)$ & $14(8.1)$ & .00 & $2.24 \pm .82$ \\
\hline Use of condom is very difficult and time-consuming & $28(16.3)$ & $20(11.6)$ & $111(64.5)$ & $13(7.6)$ & .00 & $2.37 \pm .84$ \\
\hline Use of condom is very expensive & $28(16.3)$ & .00 & $63(36.6)$ & $68(39.5)$ & $13(7.6)$ & $1.78 \pm 1.14$ \\
\hline Use of condom makes a man smart & $10(5.8)$ & $27(15.7)$ & $30(17.4)$ & $67(39.0)$ & $38(22.1)$ & $1.44 \pm 1.17$ \\
\hline $\begin{array}{l}\text { Using condom makes me feel very funny } \\
\text { Mean score } \pm \mathrm{SD}=2.46 \pm .28\end{array}$ & $51(29.7)$ & $68(39.5)$ & .00 & $39(22.7)$ & $14(8.1)$ & $2.60 \pm 1.34$ \\
\hline
\end{tabular}

\subsection{Level of Knowledge and Attitude Regarding Condom Among Participants}

Table 5 showed that all of the participants had satisfactory knowledge regarding condom but more than half $(52.9 \%)$ of the participants had negative attitude regarding condom (Table 5). 
Table 5. Level of Knowledge and Attitude Regarding Condom Among Participants.

\begin{tabular}{|c|c|c|c|c|c|}
\hline \multirow{2}{*}{ Variables } & \multirow{2}{*}{ Level } & \multirow{2}{*}{ Score } & \multirow{2}{*}{$\mathbf{n}$} & \multirow{2}{*}{$\%$} & \multirow{2}{*}{$\begin{array}{l}(\mathrm{N}=172) \\
M \pm \mathrm{SD}\end{array}$} \\
\hline & & & & & \\
\hline \multirow{4}{*}{ Knowledge } & & & & & $1.15 \pm .57$ \\
\hline & Poor knowledge & $<60 \%$ & 00 & 00 & \\
\hline & Satisfactory knowledge & $60-85 \%$ & 172 & 100 & \\
\hline & Good knowledge & $86-100 \%$ & 00 & 00 & \\
\hline \multirow[t]{3}{*}{ Attitude } & & & & & $2.46 \pm .28$ \\
\hline & Negative attitude & $1-50 \%$ & 91 & 52.9 & \\
\hline & Positive attitude & $51-100 \%$ & 81 & 47.1 & \\
\hline
\end{tabular}

\subsection{The Relationship Between Socio-demographic and Condom Related Characteristics and Total Knowledge and Attitude Regarding Condom}

The result showed that participants who had higher age $(>17)$, had statistically higher knowledge regarding condom $(\mathrm{F}=27.14, p=.000)$ compared to those who had below 18 years of age. Female participants had significantly $(\mathrm{t}=-3.719$; $\mathrm{p}=.000)$ positive attitude than male, Muslim had significantly $(\mathrm{t}=-2.871 p=.005)$ negative attitude towards condom than other. Participants who had higher level of education ( $>\mathrm{HSC}$ $1^{\text {st }}$ year $)$, had significantly higher knowledge $(\mathrm{t}=-6.276$, $p=.000$ ) compared to others. Participants those fathers' occupation had job, who had significantly higher knowledge $(\mathrm{F}=30.851, p=000)$ and positive attitude $(\mathrm{F}=7.078, p=.001)$ regarding condom and also mother's occupation had job, who had also significantly higher knowledge $(\mathrm{F}=3.222$ $p=.042$ ) regarding condom compared to others occupation.
The participants those monthly family income was $>25000$ taka in BDT, were higher knowledge $(\mathrm{F}=22.703, p=.000)$ regarding condom compared to lower monthly family income participants. The result was statistically significant. Findings showed that, participants who had 5-8 total number of family members, had statistically significant higher knowledge $(\mathrm{F}=22.703, p=.000)$ than other (3-4 members). Total source of information about condom was significant positive correlation with participant's knowledge (r-.712, $p=.000)$ regarding condom. The participants those were known someone with STDs were significantly higher BSE knowledge $(\mathrm{t}=-6.702, p=.000)$ and positive attitude $(\mathrm{F}=$ 2.606, $p=.010)$ compared to those were not known someone with STDs. On the other hand, participants those were joined to any seminar about STDs were significantly higher knowledge $(\mathrm{t}=-15.322, \quad p=.000)$ and positive attitude $(\mathrm{t}=2.584, p=.001)$ regarding condom compared to others (Table 6).

Table 6. Significant Relationship Between Socio-demographic and Condom Related Characteristics and Total Knowledge and Attitude Regarding Condom Among Participants.

\begin{tabular}{|c|c|c|c|c|}
\hline \multirow{3}{*}{ Variables } & \multicolumn{4}{|c|}{$(\mathrm{N}=172)$} \\
\hline & \multicolumn{2}{|c|}{ Knowledge regarding condom } & \multicolumn{2}{|c|}{ Attitude regarding condom } \\
\hline & $\mathbf{M} \pm$ SD & $\mathbf{F} / \mathbf{t} / \mathbf{r}(p)$ & $\mathbf{M} \pm$ SD & $\mathbf{F} / \mathbf{t} / \mathbf{r}(p)$ \\
\hline Age & & $27.14(.000)$ & & $2.85(.061)$ \\
\hline $16 \mathrm{yrs}^{\mathrm{a}}$ & $.74 \pm .23$ & $\mathrm{~b}, \mathrm{c}>\mathrm{a}$ & $55 \pm 2.39$ & \\
\hline $17 \mathrm{yrs}^{\mathrm{b}}$ & $1.37 \pm .46$ & & $54 \pm 2.51$ & \\
\hline $18 \mathrm{yrs}^{\mathrm{c}}$ & $1.32 \pm .67$ & & $63 \pm 2.48$ & \\
\hline Gender/sex & & $-.840(.074)$ & & $-3.719(.000)$ \\
\hline Male & $1.12 \pm .51$ & & $2.38 \pm .231$ & \\
\hline Female & $1.19 \pm .63$ & & $2.53 \pm .303$ & \\
\hline Religion & & $1.709(.089)$ & & $-2.871(.005)$ \\
\hline Muslim & $1.19 \pm .56$ & & $2.44 \pm .297$ & \\
\hline Others & $1.00 \pm .60$ & & $2.54 \pm .163$ & \\
\hline Educational Level & & $-6.276(.000)$ & & $-1.783(.076)$ \\
\hline HSC 1st year & $.91 \pm .36$ & & $2.42 \pm .29$ & \\
\hline HSC 2nd year & $1.40 \pm .64$ & & $2.49 \pm .26$ & \\
\hline Occupation of father & & $30.851(.000)$ & & $7.078(.001)$ \\
\hline Farmer $^{\mathrm{a}}$ & $.43 \pm .28$ & $\mathrm{c}, \mathrm{b}>\mathrm{a}$ & $2.45 \pm .270$ & $c>a, b$ \\
\hline $\mathrm{Job}^{\mathrm{b}}$ & $1.21 \pm .52$ & & $2.40 \pm .258$ & \\
\hline Business $^{c}$ & $1.38 \pm .52$ & & $2.57 \pm .290$ & \\
\hline Occupation of mother & & $3.222(.042)$ & & $.114(.893)$ \\
\hline Homemaker $^{\mathrm{a}}$ & $1.09 \pm .59$ & $\mathrm{~b}>\mathrm{a}, \mathrm{c}$ & $2.46 \pm .30$ & \\
\hline $\mathrm{Job}^{\mathrm{b}}$ & $1.37 \pm .48$ & & $2.47 \pm .21$ & \\
\hline Garments worker $^{\mathrm{c}}$ & $1.29 \pm .53$ & & $2.43 \pm .17$ & \\
\hline Monthly Income in BDT & & $22.703(.000)$ & & $1.377(.255)$ \\
\hline $15000-25000^{\mathrm{a}}$ & $.89 \pm .56$ & $\mathrm{~b}, \mathrm{c}>\mathrm{a}$ & $2.49 \pm .20$ & \\
\hline
\end{tabular}


Table 6. Continued.

\begin{tabular}{|c|c|c|c|c|}
\hline \multirow{2}{*}{ Variables } & \multicolumn{2}{|c|}{ Knowledge regarding condom } & \multicolumn{2}{|c|}{ Attitude regarding condom } \\
\hline & $\mathbf{M} \pm \mathbf{S D}$ & $\mathbf{F} / \mathbf{t} / \mathbf{r}(p)$ & $\mathbf{M} \pm$ SD & $\mathbf{F} / \mathbf{t} / \mathbf{r}(p)$ \\
\hline $26000-35000^{b}$ & $1.43 \pm .47$ & & $2.42 \pm .360$ & \\
\hline $36000-50000^{c}$ & $1.39 \pm .43$ & & $2.43 \pm .239$ & \\
\hline Total number of family members & & $11.086(.000)$ & $5.652(.004)$ & \\
\hline $3-4^{\mathrm{a}}$ & $.89 \pm .62$ & $\mathrm{c}, \mathrm{b}>\mathrm{a}$ & $2.42 \pm .15$ & $\mathrm{c}, \mathrm{b}>\mathrm{a}$ \\
\hline $5-6^{\mathrm{b}}$ & $1.21 \pm .51$ & & $2.43 \pm .31$ & \\
\hline $7-8^{c}$ & $1.47 \pm .48$ & & $2.62 \pm .30$ & \\
\hline Known someone with STDs & & $-6.702(.000)$ & & $-2.606(.010)$ \\
\hline Yes & $.94 \pm .60$ & & $2.41 \pm .29$ & \\
\hline No & $1.44 \pm .38$ & & $2.52 \pm .25$ & \\
\hline Joining to any seminar about Condom & & $-15.322(.000)$ & & $2.584(.001)$ \\
\hline Yes & $.97 \pm .52$ & & $2.49 \pm .30$ & \\
\hline No & $1.77 \pm .16$ & & $2.36 \pm .17$ & \\
\hline
\end{tabular}

\subsection{Correlation Between Knowledge Regarding Condom and Attitude Regarding Condom}

Table 7 showed, that the findings of knowledge regarding condom was significantly positive correlation with participants' attitude $(\mathrm{r}=.955, p=.004)$ regarding condom.

Table 7. Correlation Between Knowledge Regarding Condom and Attitude Regarding Condom.

\begin{tabular}{lll}
\hline Variables & $\begin{array}{l}\text { Knowledge of } \\
\text { Condom } \mathbf{r}(\boldsymbol{p})\end{array}$ & $\begin{array}{l}\mathbf{( N = 1 7 2 )} \\
\begin{array}{l}\text { Attitude of } \\
\text { Condom } \mathbf{r}(\boldsymbol{p})\end{array}\end{array}$ \\
\hline Knowledge of Condom & 1 & $.004(.955)$ \\
\hline
\end{tabular}

\section{Discussion}

\subsection{Socio-Demographic Characteristics and Condom Related Characteristics of Participants}

Socio-demographic Characteristics

The present study involved college students with the mean age of 18.1 years as it was adolescent age group, thus can help to motivate them for acquiring knowledge and developing positive attitude regarding condom to protect against both pregnancy and sexually transmitted diseases including HIV /AIDS [10]. Similar observation was revealed in Kenya and Ethiopia [17, 18]. Current study showed most of the students were Muslim, unmarried and all of them lived with their family which is consistent to a study conducted by Nesidai, 2011 in Kenya [16].

Condom related characteristics

In the present study all of the students were heard about condom but none of them had a family history of STDs. Majority of the participant's source of information about condom were radio, T. V and Newspaper which is similar to a study in Kampala [20]. Recently a study was conducted in China also revealed that main source of information was too similar with this study [14]. In the current study more than half the participants were known someone who were suffering from STDs and quarter of the students were joined in seminar about STDs. A study was conducted in Kampala among university students regarding STDs which was revealed that two third of the students were known someone with STDs due to they were regular visited to STD clinic [20] which is little it higher than current study. Researcher assumed that, lower percentage of known person of STDs due to in Bangladesh has limited STDs clinic to visit by students.

\subsection{Knowledge and Attitude Regarding Condom Among Participants}

\section{Knowledge of Participants Regarding Condom}

In the current study level of knowledge regarding condom was satisfactory among students which is similar to a study in Kenya [16]. In the present study majority participants were known that condom is a contraceptive method of family planning, condom control of family size, maintains child spacing, prevents unplanned pregnancy, prevents and control of STDs and HIV and reduces unsafe abortions which is similar to a study in Iraq $[9,16]$.

Attitude of Participants Regarding Condom

In present study more than half of the students had negative attitude regarding condom which is consistent to a study in Kenya [17]. In contrast to this study in Ethiopia, revealed that majority of the participants had positive attitude towards condom [5]. In this study most of the participants were neutral and few participants were strongly agreeing to the statement of "Use of condom interfere with romance" which is similar among undergraduate students in Kenya and Ethiopia [16, 25]. Current study revealed hat near about half of respondents agreed "Use of condom is very difficult and time-consuming "which is consistent to a study in Kenya [17].

\subsection{The Relationship Between Socio-demographic and Condom Related Characteristics and Total Knowledge and Attitude Regarding Condom}

The present study showed that knowledge and attitude regarding condom was significantly associated to higher educational level, occupation of father, higher number of family members, known someone with STDs and also history of joining to any seminar about STDs. A study was conducted in Iraq revealed that secondary school level 
participants had significantly higher knowledge and positive attitude to use condom in own life than primary level of participants and occupation, such as job and student were also revealed significantly relationship to knowledge and attitude regarding condom [9]. In the current study knowledge of participants regarding condom was significantly associated to higher age which is also consistent to a study in Iraq [9]. In this study source of information (radio, TV, newspaper, book \& magazine, poster\& billboard, peers/ friends and internet also family members) about condom was significant positive correlation with participant's knowledge which is similar to a study in China [14]. Researcher assumed that higher level of education, higher age and multiple source of information help to the students to acquire much information regarding condom which is also influence to positive attitude towards condom. In the present study indicate that female participants had significantly positive attitude than male which is similar to a study in USA [5]. This study also showed that Muslim had significantly negative attitude towards condom than other. This finding is similar to a study in Brazil [4]. Researcher indicated that religious beliefs may acts as a barrier to think positive attitude regarding condom among Muslim participants.

\subsection{Correlation Between Knowledge and Attitude Regarding Condom Among College Students}

This study showed that there was a strongly positive correlation between knowledge and attitude regarding condom among participants which is similar to a study in Kenya [16]. Researcher assumed that higher knowledge on condom influenced students to show positive attitude toward condom.

\section{Limitation of the study}

The current study has several limitations. Researcher used the back-translation method to translate scales that were developed in English into Bangla. Although researcher made effort to develop reliable scales in the Bangla language, there might inaccuracy in the process of translation and accommodating the cultural nuance. This research is also restricted by the use of face-to-face interviews to collect data; respondent bias may be occurred. This sample cannot assume to be broadly representative that limiting generalization of findings.

\section{Conclusion}

Findings showed that all of the students were satisfactory knowledge but more than half students had negative attitude regarding condom. Though near about two third students were aware about condom prevents and control of STDs and HIV but the idea of using condom did not appeal them due to their negative attitude. Participants who were Muslim by their religion had significantly negative attitude towards condom than other. Female participants had significantly positive attitude than male. The result of this study indicated that participants who were known someone with STDs and had joined to any seminar about STDs had significantly higher knowledge and positive attitude regarding condom than others. Student's age, sex, religion, education, source of information about condom was related to higher knowledge of condom among participants. Participants education and knowledge regarding condom influenced to positive attitude towards condom.

\section{Recommendations}

The findings of the current study revealed that student's age, sex, religion, education, source of information about condom, higher knowledge of condom significantly influenced to positive attitude toward condom. To increase knowledge about condom and its advantages need to arrange awareness program. Nurses should provide education and information to students about condom and its importance in life. Students awareness will help to reduce negative attitude towards condom and it will help to practice in own life that will help to prevent and protect against both unwanted pregnancy and sexually transmitted diseases including HIV / AIDS. Health professionals must be considering these findings for developing strategy to improve knowledge regarding condom which would impact to positive attitude towards condom. Further study is recommendation with involving rural students in various setting to find out the real situation and factors related to situation for generalization of the study.

\section{Conflict of Interests}

Authors have no conflict of interests and received no financial support for this work.

\section{Acknowledgements}

Researcher would like to express her hearty gratefulness to her mother and Dr. M. H Faruquee for their constructive guidance, mental support, and inspiration.

\section{References}

[1] Ahmed F, Kabir AK, Islam MS, Rouf AS. Adolescent male reproductive health knowledge and practices in Bangladesh. Dhaka University Journal of Pharmaceutical Sciences. 2008; 7 (2): $149-54$

[2] Alauddin M, MacLaren L. Reaching newlywed and married adolescents. 1999.

[3] Alauddin M, Rob U. Meeting needs of newly-married youth: The Bangladesh case. International Quarterly of Community Health Education. 1999 Jan; 18 (4): 459-69.

[4] Andrade SS, Zaccara AA, Leite KN, Brito KK, Soares MJ, Costa MM, Pinheiro AK, Oliveira SH. Knowledge, attitude and practice of condom use by women of an impoverished urban area. Revista da Escola de Enfermagem da USP. 2015 Jun; 49 (3): 364-71. 
[5] Carson C. Attitudes towards Condom Usage among CollegeGoing Women.

[6] Fikree FF, Saleem S, Sami N. A quality of care issue! Appropriate use and efficacy knowledge of five contraceptive methods: Views of men and women living in low socioeconomic settlements of Karachi, Pakistan. JOURNALPAKISTAN MEDICAL ASSOCIATION. 2005 Sep; 55 (9): 363.

[7] Gardner R, Blackburn R, Upadhyay U. Closing the condom gap. Population Reports. Series H: Barrier methods. 1999 Apr 1 (9): 1-36.

[8] Henry J. Kaiser Family Foundation. 2001. Sex education in America: A view from inside the nation's classrooms. 2008.

[9] Ismael AS, Zangana JM. Knowledge, attitudes and practice of condom use among males aged (15-49) years in Erbil Governorate. Global journal of health science. 2012 Jul; 4 (4): 27.

[10] Jain AP. Textbook of Family Medicine. Paras Medical Publisher; 2009.

[11] Joint United Nations Programme on HIV/AIDS. 2008 report on the global AIDS epidemic. Unaids; 2008.

[12] Kabbash IA, El Sayed NM, Al Nawawy AN, Shady IK, Zeid A. Condom use among males [15-49 years] in Lower Egypt: knowledge, attitudes and patterns of use. EMHJ-Eastern Mediterranean Health Journal, 13 (6), 1405-1416, 2007. 2007.

[13] Lewis M. A Brief history of condoms. BMJ books; 2000.

[14] Long L, Yuan T, Wang M, Xu C, Yin J, Xiong C, Wei S, Nie $\mathrm{S}$. Factors associated with condom use among male college students in Wuhan, China. PloS one. 2012 Dec 18; 7 (12): e51782.

[15] McDevitt TM, Adlakha A, Fowler TB, Harris-Bourne V.
Trends in Adolescent Fertility and Contraceptive Use in the Developing World, US Bureau of the Census. Report IPC/951. Washington, DC: US Government Printing Office; 1996.

[16] Nesidai KB, Ng'ang'a Z, Mwangi M, Wanzala P. Knowledge, attitude and practice factors associated with condom use among undergraduate Students of a Public University in Kenya (A case of Jomo Kenyatta University of Agriculture and Technology). African Health Sciences Journal. 2011; 19: 41-52.

[17] Ochieng MA, Kakai R, Abok K. Knowledge, attitude and practice of condom use among secondary school students in Kisumu district, Nyanza province. Asian Journal of Medical Sciences. 2011 Feb 25; 3 (1): 32-6.

[18] Regassa N, Kedir S. Attitudes and practices on HIV preventions among students of higher education institutions in Ethiopia: the case of Addis Ababa University. Educ Res. 2011 Feb; 2: 828-40.

[19] Retrieved from UN Population Projections 2010; BDHS; 2011.

[20] Sekirime WK, Tamale J, Lule JC, Wabwire-Mangen F. Knowledge, attitude and practice about sexually transmitted diseases among university students in Kampala. African health sciences. 2001; 1 (1): 16-22.

[21] UNICEF. HIV and AIDS in Bangladesh; 2009.

[22] World Health Organization. World health statistics 2009.

[23] World Health Organization. World health statistics 2011.

[24] World Health Organization. World health statistics 2012.

[25] Silassie AG, Giorgis MW, Kahsay N, Fisaha Y, Zerihun Z, Tadesse K. Knowledge, attitude and practice of condom utilization among Axum preparatory school students. J AIDS Clin Res. 2016; 8: 2016. 